\title{
Language and Nationality ${ }^{1}$
}

\author{
Oleksandr Potebnia ${ }^{2}$ \\ Translated from Russian by Richard Hantula
}
There is a rather widespread belief that the originality of a nationality stands in direct relation to the degree of its estrangement from others and in inverse relation to its degree of civilization. Adherents of this belief explain it approximately as follows.

We see, they say, that at the present time originality of manners, customs, and dress can be found only in remote corners of Europe, whereas in olden days it was a different story. Now the resident of an out-of-the-way place in Germany or France does not even look like a German or a Frenchman but bears a quite particular impress that belongs solely to the area in question. In contrast, in a civilized man, especially a man who has travelled much about Europe, there appears a general cultural type that is no longer characteristic of a Frenchman, Englishman, or German, but of a civilized man in general. Educated men of all nations have more in common, not only in theoretical convictions but also in features of character, than do the educated members of a people and their uneducated compatriots. Persuasive evidence of this, incidentally, is supplied by comparing oneself and one's acquaintances with, on the one hand, heroes of foreign novels who are in the same social position and, on the other hand, representatives of the common people in Russian stories.

This phenomenon is the result of two factors acting jointly, namely, the advances of human thought directed at the study of nature, and man's innate imitativeness.

No matter what the origins of the diversity of nationalities, it is in any case supported by spatial dissociation and the diversity of geographical

\footnotetext{
1 The article was first published in Vestnik Evropy, vol. 5, no. 9-10, 1895, pp. 5-37. All original footnotes have been preserved. Explanatory notes have been provided by Marko Robert Stech (CIUS) and will be given in square brackets and identified as such in the footnotes. Bibliographic references have been reformatted according to MLA, as per EWJUS's style guidelines.

2 An article recovered from the papers of the late Professor Oleksandr Potebnia by intimates of his. [Ed.] [This note was in the original; the abbreviation "Ed." refers to the Vestnik Evropy (Herald of Europe) editor at the time, Mikhail StasiulevichMarko Robert Stech.]
} 
influences. But intercourse between human beings is facilitated and increased by inventions such as steamships, railroads, and telegraphs. The constraints of geographical conditions lose their force as, thanks to his power over space, man acquires the opportunity to change his place of residence and create for himself an artificial environment more propitious for life than any of those provided by nature. The mixing of members of different peoples entails the crossing of kinds and the formation of general types. Everything that increases intercourse between human beings strengthens the levelling action of imitativeness, which from time immemorial has been characteristic of man-imitativeness at first reflex and involuntary, then conscious and critical. Imitativeness brings about a merging of tribes into peoples, by analogy with which it can be expected that sooner or later, let say in several thousand years, peoples will merge into one common human nationality. The possibility of this happening is indicated in the past and present by phenomena such as the dissemination of the culture of a certain people to many others and the replacement of national cults by Christianity, which does not recognize national differences. When one of two peoples borrows from the other, for example, the jury system, and the second from the first the system of peasant life, then the two become more alike than they were previously.

The obstacles to borrowing and imitation posed at the present time by the diversity of languages may be smoothed over and may disappear. Indications of this are to be found in the present. Earlier as well, languages such as Greek and Latin existed whose influence extended far beyond their original borders. Now the educated of all nations possess international languages, knowing which one can cross the entire globe. Besides the exclusive universality of the so-called world languages, we see that as soon as several tribes settle in a given area and necessity forces them to strive for mutual understanding, a community of language is established between them in two ways. Either the language of the stronger tribe supplants the language of the weaker, which therewith disappears (for example, the dialects of the Russianized Finns), or the mixing produces amalgamated languages such as English, French, Italian, Spanish, and Hungarian.

To this is added the belief that the ever-increasing number of translations from one language to another, that is, the increase of the quantity and intensity of efforts to convey by the means of one language what is said in another, should smooth over their differences. Moreover, it is supposed, higher development weakens the sound element in a language and strengthens the logical, which can be regarded as common to all men, and removes from usage original turns of phrase and proverbial expressions. 
One of the leading authorities in Slavic linguistics, Franc Miklošič, is of the opinion that in the languages of Europe a common modern European syntax is arising, based on the syntax of the classical languages.

These familiar considerations oblige us to suppose that the course of human development, directed toward the liberation of man from the pressure of external nature, also gradually relieves him of the fetters of nationality. At the same time, it is postulated that the existence of one common human language would be just as much in accordance with the higher needs of man as the artificial living conditions thanks to which tropical fruit is now available in St. Petersburg are convenient [in our daily lives].

To these considerations we oppose others that have greater force for us.

1) What significance does imitativeness have in personal life? An individual in all spheres of life is something largely independent with respect to the influences of other individuals and the rest of nature. Man in this respect, as in others, is the end of a series of lower creatures. Every force acts upon him precisely by being altered in him and provoking a counteraction in him. Imitation that is provoked in man by a certain action cannot be an identical repetition of that action because, for such a repetition, the imitator would have to be identical with what produced the action; moreover, he would have to be in the very same circumstances. The latter is impossible by the physical law of impenetrability alone, not to mention the more complicated laws of thought. If these a priori considerations are insufficient, then one can assure oneself by simple observation that reflex imitation-imitation not reaching the subject's consciousness - of another's movements and sounds yields movements, even under the most favourable conditions, that are merely similar but not identical. At the higher stages of mental life, the imitation of another person either is the understanding of his movements and sounds (so that, paraphrasing " $d u$ gleichst dem Geist, den $d u$ begreifst" [You resemble the spirit that you understand], one can say that "das Gleichen" [resembling] is only "das Begreifen" [understanding], or presupposes this understanding). ${ }^{3}$

But it is well known that mutual understanding is not a shifting of one and the same content from one head to another but consists in person $\mathrm{A}$, who has connected the content of his thought with a certain external sign (movement, sound, word, image), evoking in person B a corresponding content. Those who understand each other may be compared with two different musical instruments brought into such a relation with each other

3 [Translations from German are by Myroslav Yurkevich (CIUS)-Marko Robert Stech.] 
that the sound of one of them evokes not the same but a corresponding sound in the other. How by the word candle can I understand exactly the same thing as my interlocutor when our organs of perception are different and our accumulations of memories (about it) are yet more different? Hence is explained the paradox that all understanding, even the fullest, is at the same time misunderstanding. Man cannot escape the circle of his personal thought. ${ }^{4}$ What is called the common level of thought between human beings is possible solely thanks to the capacity for abstraction, that is, the reduction of a real difference between thoughts in different subjects to a certain minimum of difference, and thanks to the fiction consisting in the acceptance of this minimum as an equivalent of complete thoughts.

These elementary points, which, however, are ignored by many, explain a great deal to us. In all spheres of human life "dependence" ("nesamostoiatel'nost"') and "imitativeness" express only certain more or less low degrees of difference in the independence and originality of thoughts and actions. In another, absolute sense, these concepts are impossible.

Thus, for example, one can forge signatures, but a magnifying glass will reveal the forgery. Writing samples can be carefully copied, but it is impossible to reproduce the person's handwriting exactly. Much can be achieved through upbringing. A man can be made more or less energetic, knowledgeable, or upright, but he cannot be deprived of his individuality; he cannot be made totally like a stereotype.

Since peoples consist of individuals and come into contact with each other through the intermediacy of individuals, everything that has been said about the originality and insularity of the individual understandably applies to a people insofar as its unity is analogous with the unity of an individual. The mutual influence of peoples is also only mutual stimulation. ${ }^{5}$ The dissemination of one people's culture to others seems to us a uniting of peoples only so long as we wander in the cold heights of abstraction. Some features whose repetition we notice in the lives of different peoples actually exist as concrete phenomena only in groups of a large number of other features. In view of this consideration we are compelled to say, for example, not that a single and immutable Christianity spread through the civilized world but merely that Christianity in the form of an initial and distinct stimulus occasioned an entire chain of

\footnotetext{
${ }^{4}$ A man's thought and feelings are inexpressible, although we need to believe the opposite; hence this inexpressibility is acknowledged and even becomes a guiding principle only in exceptional moods: "Be silent, be reticent, and conceal" (Fedor Tiutchev, "Silentium").

5 On imitativeness as a means of formation of nationalities, see Bedzhgot $134 \mathrm{ff}$ (translation of Walter Bagehot, Physics and Politics).
} 
Christianities that are very different from one another, if examined concretely. These are not only Eastern and Western but also Russian, Polish, and German Christianity, and even German Christianities. The crux of the matter is that one should not take one's abstractions for what is essential-this, however, is done when Christianity, for example, is examined independently of the milieu in which it appears.

Another example that explains the qualities of tradition is migrating stories and tales. Thanks to such experts in a special kind of literary research as Theodor Benfey, Felix Liebrecht, and many others, we can say of many works that their motifs have circled almost the entire globe; the motifs have come to and remained with a great number of peoples, starting with the Japanese and the Hottentots. These wanderings would seem to be obvious evidence of the capability of all peoples to reproduce one and the same content. But a question arises as to whether we have grounds for calling these geographical and chronological movements life in the sense in which we ascribe life to a language. Of course we do. If this is so, then we should apply to the migrating literary motifs the same view that we hold regarding linguistic forms. The importance of a grammatical form lies in its function, which, of course, must have a point of attachment. Similarly, the main thing in a migrating story is how it works, that is, how it is understood and applied at each stop on its road. The highly estimable literary investigations of these stories as regards their abstract identity in character and significance are equivalent to grammatical investigations that examine not forms but prepared specimens of them devoid of function, that is, of life. The recognition that the motifs of migrant tales are immutable is equivalent to the prevailing opinion that the meaning of a root remains immutable throughout an entire family of words and falls together with the family.

The same can be said of all artistic works. Their life consists in their being understood and in how they are understood. Otherwise, it is worth talking about them no more than about a block of stone, a piece of canvas, etc. If this is true, then who will assert that the understanding and influence of works of Greek sculpture are the same now as in the time of Greece's flowering? Then and now-they are entirely different works of art that share merely the same material substratum, but not the same soul, so to speak. These differences vary not only with time but also with peoples.

Were languages but means of presenting ready thought that takes shape apart from them, as was actually believed in the past century and to some extent even in the present one, their differences with respect to thought could then be compared with the differences in handwriting and type for one and the same alphabet. It is more or less all the same to us with what handwriting we write or in what type a book is printed, as long as the result can be read. Thus it would make no difference to thought in 
what language it be expressed. Given this state of affairs, as soon as the conviction spread that the difference between languages is only superficial and inconsequential, and that one's attachment to one's language is only a matter of habit that lacks deep roots, people would probably begin to change their language as easily as they change their clothes. As a result one could expect that, just as for the sake of convenience philologists adapt Latin characters to a great number of different languages, and that just as common systems of measures and weights are established, sooner or later an entirely artificial, maximally easy and simple common language would be accepted. One could expect that once this language appeared at the higher strata of the intelligentsia, which even now possesses general artificial languages for the eyes, such as numbers and algebraic, chemical, and meteorological signs, it would gradually descend into the lower spheres and finally embrace all of mankind. But our century has discovered that languages serve to present thought only because they are a means of processing the initial, prelingual elements of thought; hence they may be called a means of creating thought. Languages differ not only in the degree of their convenience for thought but also qualitatively, that is, in such a way that two compared languages can have an identical degree of perfection despite profoundly different structures. The universal qualities of language are articulateness with regard to sounds and, internally, the fact that they all are systems of symbols in the service of thought. Furthermore, all their remaining qualities are tribal rather than universal. There is not one grammatical or lexical category that is obligatory for all languages.

At the present time linguistics for the most part is not in a position to follow how the initial thought processes conditioned by language influence the complex products of thought. Nonetheless, the thesis that these processes are much more important for the perfection and quality of the product of thought than, for example, the methods, instruments, and materials of drawing, painting, and engraving are for the works of those arts is a strong one. These processes, whether we know of them or not, certainly influence everything that thought may create through the medium of language. ${ }^{6}$

Examining languages as profoundly different systems of ways of thinking, we can expect from the presumed replacement in the future of the diversity of languages by one universal language simply a lowering of the level of thought. For if there is no objective truth, if the truth accessible to

\footnotetext{
6 Grammatical categories and general levels of philosophical thought parallel to them are created only with the assistance of language; they do not exist outside language, and they differ in various languages. The very content of thought bears a different relation to those categories in various languages, even languages of related peoples living under similar physical conditions.
} 
man is only an aspiration, then the reduction of the various directions of aspiration to one is not a gain. Language is not just a particular system of ways of cognition, just as cognition is not isolated from other aspects of human life. The cognizable acts upon us aesthetically and morally. Language is at once a means of consciousness of both aesthetic and moral ideals, and in this regard the diversity of languages is no less important than it is in its relation to cognition.

Language can be compared with vision. Just as the slightest change in the structure of the eye and the operation of the visual nerves inevitably yields different perceptions and thereby influences a person's entire world view, so every trifle in the structure of a language must yield, unknown to us, its own particular combinations of elements of thought. The influence of every trifle of a language on thought is in its own way unique and not replaceable by anything.

When a man who is bilingual passes from one language to the other, he alters at the same time the character and direction of the course of his thought. Moreover, this occurs in such a way that the exercising of his will merely changes the track of his thought, and its influence on the further course is only indirect. His exercise of will may be compared with what is done by a switchman who transfers a train to another track. (This was recognized more or less clearly long ago, in the dedication to Mikhail Lomonosov's grammar.) And conversely, if a speaker is accustomed to using two or more languages, then as the content of his thought changes he automatically turns now to one, now to another language. I believe this can be observed in certain West Russian documents in which, depending on the subject, there appears now a Polish, now a Little Russian, now a Church Slavonic stream. This phenomenon is the real basis of Lomonosov's division of style into high, middle, and low.

An example of the same thing is supplied by the bilingualism of the upper classes of Russian society. [Ivan Aksakov says the following]:

In the family of the Tiutchevs, which was entirely Russian, French reigned almost exclusively, so that it was in French that not only all conversation but even all the correspondence of the parents with their children and the children among themselves was conducted, both then and subsequently throughout their lives. The dominance of French did not exclude in Ekaterina L'vovna (Fedor Ivanovich Tiutchev's mother, who died in 1866 in the ninetieth year of her life) an attachment to Russian customs, and it co-existed surprisingly well with her reading of psalters, horologions, and prayer books in Church Slavonic in her bedroom and, in general, with all the characteristics of Russian Orthodox and gentry life. This phenomenon, however, was quite common at the end of the eighteenth and the very beginning of the nineteenth century, when the Russian literary language was still rather new and was still merely the property of fanciers of 
literature, and, moreover, was not yet sufficiently adapted and refined to express all the requirements of the social life and knowledge acquired from Europe. Together with the ready Western civilization, a ready foreign instrument for the exchange of ideas was also borrowed. Many Russian statesmen who presented their opinions superbly in French wrote Russian in the clumsiest and most barbaric fashion, as if they were leaving a smooth road for the hard clods of a field that had just been plowed. But often, simultaneously with the purest French jargon and ... from one and the same lips, one could hear living, idiomatic speech, almost that of the common people-speech more folkish, in any case, than our present-day bookish or colloquial language. Of course, this spoken language was more often used for intercourse with the domestic serfs and with the lower strata of society, but nonetheless this rude contradiction, this sharp feature of daily life, side by side with fidelity to everyday Orthodox traditions, explains a very great deal in the history of our literature and of our national self-consciousness (9-10).

Is it not strange that despite all the acuteness of the folk (?) tendency of thought in Tiutchev, our high society, "high life" [in English in the original] not only did not reject Tiutchev and did not subject him, like the Slavophiles, to derision and persecution, but always considered him one of their own-at least the intellectual stratum of that society? Of course, the reason for this was the charm of all-round culture, a charm that in Tiutchev was so inseparable from his being and attracted everyone, even those who disagreed with his political beliefs. Those beliefs seemed to deserve regret as the extremity, originality, capriciousness, and paradoxicalness of a strong mind and were readily forgiven Tiutchev for the sake of his brilliant wit, sociability, and affability; for the sake of the refined, elegant Europeanism of his whole appearance. Moreover, all Tiutchev's "national ideas" seemed to society something abstract (as, apparently, they indeed partly were in him), a matter of opinion (une opinion comme une autre!), not a matter of life. In point of fact, they brought neither exclusiveness nor intolerance into Tiutchev's treatment of people. He belonged to no literary camp and maintained relations with members of all circles and camps. They did not alter his habits. They did not remake his private daily life. They did not impose on him any stamp of party or nationality .... But was this Russian element in Tiutchev really nothing but abstraction or thought, only a matter of opinion? No. A love for Russia, a faith in its future, a belief in its supreme historical calling possessed Tiutchev powerfully, unyieldingly, and undividedly from his earliest years to his last breath. They lived in him at the level of an elemental force more dominant than any other personal feeling. Russia was for him the highest interest of his life; all his thoughts on his deathbed were fixed on it. But at the same time it is strange to think that the poem on the occasion of a visit to a Russian village ("Oh, no, not here, not this barren land was for my soul its native land") and the poem "These Poor Settlements" were written by one and the same person (Aksakov 75-76). 
Fedor Ivanovich Tiutchev is a splendid example of how the use of different languages gives thought different directions, or, conversely, of how, sensing the direction his thought will take in the following moment, a man takes up one of the languages available to him. Two kinds of intellectual activity go in one direction, interweaving with each other but preserving their separateness, throughout his life, until his final days. They are, on the one hand, the writing of poetry in Russian and, on the other hand, the thinking of a political figure and diplomat, a man of the world in the best sense of these words, in French. [As his biographer writes],

In the twenty-two years of his almost uninterrupted residence abroad, he heard almost no spoken Russian, and after the departure of Khlopov (Tiutchev's former serf male nurse-they had a close mutual friendship) he completely lost the small but salutary contact with Russian domestic life that was supplied him by Khlopov's presence in Munich. Tiutchev's first wife did not know a word of Russian, nor did his second, who learned Russian after moving to Russia (as a matter of fact, in order to understand her husband's poetry). Hence the very language of his domestic life was foreign. As was the custom then, conversation with Russian travellers was always conducted in French. Both his diplomatic correspondence and his correspondence with his relatives were conducted exclusively in French (Aksakov 53).

By his own acknowledgment, he expressed his (prose) thinking more soundly in French than in Russian. He wrote his letters and articles exclusively in French. He spoke, of course, nine times more French than Russian in his life. Meanwhile, Tiutchev's verse was composed only in Russian. So poetry welled up from the very depths of his spirit, from depths unattainable even to his own will-from the recesses where our prototypical natural element lives, where man's very truth dwells (Aksakov 85).

His poems were not the fruit of work, which even if inspired remains work and at times is even painstaking in many poets. He did not write them but wrote them down. The best ones were created instantly.

Tiutchev represents an instructive example not only of the fact that different languages in one and the same person are connected with different spheres and modes of thought, but also of the fact that these different spheres and modes in one and the same man are differentiated materially. During his final illness, with half of his body affected by paralysis, Tiutchev preserved almost until death his capacity for brilliant French conversation and his lively interest in politics. Once, after a prolonged fainting fit, his first words were: "What is the latest news from Khiva?" Meanwhile, his power over verse and his sense of poetic measure left him much earlier. He would try to compose poems, but nothing would come of it. 
To know two languages at a very early age is not to possess two systems for representing and communicating one and the same circle of thoughts. Rather, this circle is divided in two, and in advance the achievement of a wholeness of world outlook is made difficult; scientific abstraction is hampered. If the language of the school is different from the language of the family, it should be expected that school and home life will not co-exist harmoniously but will clash and struggle with each other. A child who says $d u$ pain to his parents and governess and (in secret) khlebtsa to the servants has two different concepts of bread.

When two persons who speak the same language understand each other, the content of a given word is different for both speakers, but the representation is so similar that it can be taken as identical without noticeable harm for the investigation. We may say that by means of the word in question speakers of the same language examine different contents of the word in themselves from the same angle, from one and the same point of view. In the case of translation into another language the process becomes more complicated, for then not only the content but also the representation is different.

If a word of one language does not cover the word of another, still less can combinations of words, images, or feelings stimulated by speech cover each other. Their point disappears in translation. Witticisms are untranslatable. Even a thought torn away from its association with its verbal expression does not cover the thought of the original. ${ }^{7}$ And this is understandable. Let us assume for a moment the possibility that a thought being translated stands before us already devoid of its initial verbal envelope but not yet clothed in a new one. Obviously, in such a state this thought, as an abstraction from the thought of the original text, cannot be equal to it. When we say we take what is essential from the thought of the original, we are reasoning as if we were to say that what is essential in a nut is not the shell but the kernel. Indeed, essential ("genießbar") for us but not for the nut, which could not develop without its shell, just as thought of the original could not develop without its verbal form, which is part of its content. A thought translated into another language receives new additions by comparison with its fictitious abstract state; these new additions are inessential solely from the viewpoint of its initial form. If in comparing a phrase of an original text with a translation we often find it difficult to say how much the associations stimulated by the one and the other differ, this is the result of the imperfection of the means of observation available to us.

7 A familiar idea not requiring citations for confirmation. Compare, however, Mommsen 9 and passim. 
In this case as in others, poetry points out the way to science. There exist amusing stories portraying the impossibility of expressing in one language what can be expressed in another. For example, in Vladimir Dal': a visiting Greek was sitting by the sea. After singing something to himself, he tearfully began to cry. A Russian who happened to observe this asked him to translate the song. The Greek translated: "A bird was sitting, I do not know what it is called in Russian, it was sitting on a hill, it sat for a long time, flapped its wing, and flew far, far away, through the forest, far away . . .. And that is all. In Russian it does not come to anything, but in Greek it is very sad!"8

In actuality, every translation is more or less like the well-known Great Russian comic adaptation of the Little Russian "Oi buv ta nema" [Engl., "Oh, he was here, but he is gone"; Russ., "Ekh byl, da netuti"]. Even a slight alteration of a sound that seemingly has no bearing at all on the word's content noticeably alters the word's impression on the listener. Probably, many have experienced an unpleasant impression of falseness and insincerity while listening to a singer or an actor speaking in a dialect unfamiliar to him so as to please the local public. Art here turns into dissimulation.

Apropos of the impossibility of a poet's writing in an alien language, Ivan Turgenev said the following: "Never in my life did I print a single line that was not in Russian. Otherwise I would not have been an artist but simply a good-for-nothing. How is it possible to write in an alien language when one can hardly cope with images and thoughts in one's own native tongue," etc. (Polnoe sobranie pisem 261).

The very observance of differences in effects becomes more difficult when we deal with words of the same origin in both languages. That which is similar in two languages of the same origin results not from the paths of their development actually coinciding but from their running almost parallel alongside each other for a certain time after separating at one point. The fact, however, that translation from one language to another is not the transmission of the same thought but the stimulation of another, different thought applies not only to independent languages but also to dialects of one and the same language having much in common. "I once asked a Ukrainian," says Pigasov in Turgenev's Rudin, "to translate the following sentence, which was the first one to come to mind: 'Grammar is the art of reading and writing correctly' ('Grammatika est' iskusstvo pravil'no chitat' i pisat"). Do you know how he translated it? [The same thing with a southern accent.] ('Khramatyga e vyskustvo pravyl'no chytaty $i$ pysaty'). Well, is this a language, in your opinion? An independent

\footnotetext{
8 [No source is given for this citation-Marko Robert Stech.]
} 
language?"9 The very fact that translation from a literary language to a regional dialect and from one regional dialect to another very often seems a parody, precisely this is evidence that, anticipating science's solution, unerring instinct understands the most similar dialects as different musical instruments that perhaps are sometimes related to each other as a church organ is to a balalaika but nonetheless are not replaceable by each other. In order that this be so, one does not have to try one's hardest to make a sentence in the dialect utterly unlike a sentence of the literary language, as used to be done among us by certain enthusiastic supporters of the independence of the Little Russian language. That is like carting firewood into a forest. There are feelings and thoughts that no talent can evoke in a people's common literary language but that are comparatively easily evoked in a regional dialect. There are writers who are mediocrity itself when they choose the literary language as their medium but who are deeply artistic and truthful in their native dialect. As scientific materials, their creations cannot be replaced by any editions of monuments of folk poetry, collections of words and phrases, customs, beliefs, and the like. We have such writers. The Germans have them as well and highly value their influence on the common German language and literature.

This opinion of dialects and subdialects is widely current and does not require corroboration by authorities. Nevertheless, one can find enough of such corroborations. Compare, for example, Jacob Grimm's opinion that should the Czech and Polish dialects disappear from the common Slavic language, as some imagine to be possible and desirable, this would deserve regret, for each of these dialects has its irreplaceable advantages (105). Here it is a question merely of forms like the dual, but it could be said, with considerable grounds, of the entire system of the language. "Only in rare instances," says Wilhelm von Humboldt, "can one discern a definite connection between the sounds of a language and its spirit. Even in dialects (of the same language), however, insignificant alterations of vowels that little change the language on the whole can by rights be associated with the condition of the spirit of the people ('Gemütbeschaffenheit'), analogously with the Greek grammarians' observations about the more manly Doric $a$ as compared with the more delicate Ionic $o e^{\prime \prime}$ (272).

Returning to [the topic of] the influence of foreign languages, we see that were the knowledge of foreign languages and translations from them in every case a levelling means, translators who were strong in their language and translations that were exemplary by their originality and artistry of language would be impossible. At the same time, there are

${ }^{9}$ [No source is given in Potebnia's text for this quotation; however, the quote is from Ivan Turgenev's novel Rudin. The edition closest to Potebnia's lifetime is Turgenev, Polnoe sobranie sochynenii 319-Marko Robert Stech.] 
known translations of, among others, books of Holy Scripture that surpass many original works in the attributes mentioned and in their influence on the independent development of literature. Even in school, translations from foreign languages to native idiom, if certain conditions are observed, prove to be a powerful means of strengthening the pupils in the spirit and traditions of their native tongue and of stimulating independent creativity in it. The conditions mentioned are two. On the one hand, the pupils' acquaintance with foreign languages should be begun only when their knowledge of their own has become sufficiently strong. On the other hand, the pupils' language should be the teacher's mother tongue, and the teacher should be in a position to require of the translations accuracy and agreement with the demands of this native language. The predilection of many Russians of classes patronized by fortune for teaching children modern foreign languages deserves censure not for itself but for the baseness of its motives. Such Russians view the knowledge of foreign languages as a means of distinguishing oneself from the common people and as a means of intercourse with foreigners. In the latter aspect they do not endeavour to win the foreigners' respect but only to talk like them. In language, sounds alone and not thought are seen, and that is why, for the sake of purity of accent, the teaching of a foreign language is begun almost in the cradle. As in the times of [Denis Fonvizin's play] Nedorosl' (The Minor), children are entrusted to Wralmans. ${ }^{10}$ Thus children with decent capabilities turn out as semi-idiots-living monuments of their parents' thoughtlessness and servility of soul.

As for remarkable human beings like Tiutchev, who in childhood mastered a foreign language together with a rich stock of content and did not lose the capability to produce in their native tongue, in them the activity of thought in a foreign language doubtless worked to the detriment not only of thought in their native tongue but also of general productiveness. In Tiutchev himself one can note the narrowness of the sphere embraced by his Russian. He would have done more if, given the same talent and the same kind of activities, he had possessed a command of but one language and studied others only to the extent necessary to stimulate his thought as it moved along the rails of his native language.

Although bilingualism in members of the upper circle has not been a rarity in Russian society of the eighteenth and nineteenth centuries, they nonetheless constitute not the rule but the exception. Besides, we are moving away from this condition and not toward it. The influence of

10 [Adam Wralman is a character in Fonvizin's play The Minor. He is a German governor (i.e., house teacher and academic mentor of young boys) in a house of a Russian landowner-Marko Robert Stech.] 
bilingualism on the broader classes of the population, on almost entire, though not numerous, peoples like the Czechs, I think, is also unfavourable.

It can be accepted as a rule, at least for modern times, that the flowering of independent national creativity in science and poetry is always preceded by periods of imitativeness that presuppose a more or less theoretical or practical, a more or less deep and widespread knowledge of foreign languages. In proportion with the increase in the quantity of good translations, is an increase in the people's reserve of strength, which sooner or later finds an outlet in more original creative work. Strictly speaking, imitativeness and independence are here understood in the same way as necessity and free will. Where the first impetus is still visible, as in the first bounce of a billiard ball from the billiard cushion, the words imitativeness and necessity are used. Where between the stimulus and the response there appears an intervening medium masking the stimulus, it is called independence and freedom. But imitativeness is also originality, an obvious proof of which is supplied, incidentally, by our imitative literature. In fact, there are more independent products of thought in it; only scholarly study reveals traces of an external impulse.

Speaking about the relations of peoples with equal rights, one might think that their originality would be effaced if their association with others increased in greater progression than their domestic associations. But to increase their individuality it is sufficient even that their internal and external intercourse be intensified in equal measure. Meanwhile, it seems more probable that among the large national masses of Europe the internal intercourse of peoples is increasing in greater measure than the international, except, of course, in those cases where the regular course of affairs is altered by force of arms or political trickery.

The differentiation of initially similar languages does not mean that the capability of stimulation by other languages decreases in peoples. It does, however, seem to me to mean that both an individual and a people find it more difficult every year to get out of the rut being made for them by their language, precisely to the degree that the rut becomes deeper. From this point of view it seems that the more archaic the language of a people, and the less sharp the revolutions that occur in it during the time separating it from its beginning, the greater the possibility of its denationalization.

It is extremely naïve to think that a good translator has the ability to jump out of his national skin and enter into a foreign thought, and that supposedly the very thing that makes Germans the "best in the world" as translators makes it easier for them to change nationality and is responsible, for example, for there being so many German surnames among the Slavs (Rüdiger 118). There is no denying that German literature contains a great number of outstanding translations from a great many languages of the globe. Germany is the country of philology, the homeland 
of comparative linguistics. But all this depends chiefly on the degree of educatedness, on the extent of the demand for learned men, and on the number of the latter who expend their intellectual labour on the study of foreign languages and literatures; only to a lesser degree does it depend on the general qualities of their nationality and languages. Here it is necessary to distinguish between theoretical and practical knowledge of a language, that is, facility in thinking and speaking in it. In the latter respect the Germans stand below the Slavs, and if in general they can take pride in anything, then on that basis they can pride themselves on the greater insularity and stability of their nationality. Were the closeness and geographical proximity of languages the main factors providing theoretical knowledge of them, then the Russians and Poles would possess such knowledge of the Lithuanian language, and we would learn that language from them and not from August Schleicher. Meanwhile, it is well known that many categories of the Slavic languages, not to mention sounds, in practice present an adult German, whether educated or of the common people, with difficulties that cannot be overcome for entire decades. From this we may judge their capacity for knowing languages less akin to German.

I do not know of precise observations regarding this question, but it seems to me that there hardly will be found among German common people so many with a practical knowledge of foreign languages as among Russians who have relations with non-Russians, for example, in the Caucasus and in Siberia. But I do not think that an adult Russian can fully master any foreign language, for instance, with respect to sounds (although the range of sounds possessed by a Russian, in particular a man of experience who knows Polish, and, conversely, by a Pole who knows Russian, which often occurs, is much more extensive than that possessed by a German). It is not, however, only my personal opinion that he will more quickly learn German and French than a German or a Frenchman Russian. It is difficult to think up anything more superficial than the opinion that the German is a cosmopolite by the character of his nationality, while the Frenchman, for example, is only a Frenchman, and the German alone is a man. The Germanophiles' complaints that where German migrants are not isolated, as in Russia, they lose their nationality presuppose a strange and unrealizable wish that the influence of the remote abandoned fatherland on the second and third generation of German migrants be stronger than the influence of the milieu surrounding them.

It goes without saying that if it is impossible to recognize as absolutely denationalizing the study of foreign languages and the literary (influence) that we can observe in our time, then the same can be said of such phenomena in the past. Prehistoric traces left by the mutual influence of 
peoples have a primarily, if not exclusively, lexical character. But it is precisely the lexical side of the language that is most capable of enduring the pressure of external influence without changing. Speaking a priori, every foreign word in new soil must change; countless are the examples where such a change in both sounds and meaning is so obvious that it does not require proof. The particularity and originality of peoples can be thought to exist not in defiance of their mutual influence but in such a way that one of the chief circumstances favouring the development of a people is a stimulus from outside smaller than what is obtained within. Similarly, according to Humboldt, the influence of a speaker's personality on another's consists not in the supplanting of this latter but in stimulating it to new fruitful activity (213). The mutual stimulation of peoples presumes not assimilation but merely mutual adaptation, which can be compared with what takes place between flowers, which nourish insects, and insects, which assist the fertilization of flowers.

What meaning does denationalization have after this? It consists in a transformation of the national life where the tradition of the people, which lies mainly in language, is interrupted or weakened to such a degree that it is only a secondary factor of the transformation. Instances of complete denationalization can be observed only in the lives of individuals who were transferred into the milieu of another people before they learned to speak. In such cases the life of the individual's ancestors enters into his development only in the form of physiological vestiges and inclinations in his emotional life. With regard to entire nationalities, which necessarily consist of individuals of different ages, such cases are impossible. Here denationalization presumes with certainty only the weakening of tradition between the adult and the rising generation, that is, the individual removal of the latter from the influences of the family. Let us assume the most favourable conditions for denationalization, namely, that the repressed people do not lose its property and is not subjected to slavery in its crude form, and that its rising generation is given, in place of the family, the best educational surrogate for the family-the school. In accordance with our assumption, however, this school does not use the language of the pupils as a ready educational medium but teaches them a new language and thus wastes time in making a kind of palimpsest out of their consciousness. Other things being equal, the pupils of such a school will obviously be lower in all respects than those who, on entering the school, did not have to forget but had only to learn, adding school crumbs to the huge stock of preschool reserves of thought. We will obtain similar results if in place of the school we substitute other educational media that are embraced by the concept of life in society. Thus, for a people undergoing denationalization the natural course of affairs gives rise to unpropitious conditions of existence that result from intellectual subordination. The less the repressed people are 
prepared to master the language of the repressing people, the more significant will be this subordination. During such a breakup the abomination of desolation is inevitably enthroned in place of the forms of consciousness being supplanted and occupies this place until the supplanting language becomes native and accommodates itself to its new people. As a rule, human beings do not voluntarily give up their language, among other reasons because of an unconscious fear of the devastation of consciousness. For, until we learn a better view, we hold to Humboldt's opinion that "no people can vivify and fertilize an alien language with their spirit without transforming that language into a different one" (203). In other words, a nationality that is being absorbed by another introduces into it elements of disintegration; of course, the more numerous, morally strong, and original is the nationality that is being absorbed, the more quickly will these elements yield noticeable results, and vice versa.

Applying this to Russia, I think that, a priori, there is no doubt about the influence on the formation of the Russian nationality of the Finnic and other tribes that have not died out but have been absorbed by the Russians. The suggestions of individual cases of this influence, however, except for certain lexical borrowings, are for the most part false. Thus, the opinion that from the point of view of language the Great Russian tribes are indebted for their existence to the influence of the Finns remains false, since, given the present resources of linguistics, no trace of outside influences can be discovered in the grammatical structure of the Great Russian dialects.

Returning to denationalization and the break with tradition, it should be added that from the point of view of language one should by no means understand by this concept what the champions of the idea of nationality understand by it when, for instance, they complain of the schism between the upper and lower strata of the Russian people and between pre-Petrine and post-Petrine Rus'. The national tradition or the development of national life without leaving the tracks has much in common with the tradition of a religion or scientific tendency. What seems from one point of view the betrayal of certain principles appears from another to be but their development, for development here is only a different aspect of the preceding moment. A man raised on the dogmas of a certain religion who then comes to deny them belongs to that religion by his moral makeup just as much as one of its obedient sons. Western Protestantism belongs to the school of Catholicism, Russian dissidents to the school of Orthodoxy. This idea, which was voiced among us long ago, if I am not mistaken, by one of the Slavophiles, I now find in Heymann Steinthal. A Catholic, a Protestant, and a Jew who agree in their religious and philosophical views each give their own historical lining to those views ("Zur Religionsphilosophie," 26667). The same obtains in the sphere of science. The followers of Jacob 
Grimm and Franz Bopp demolish stone by stone the edifice erected by their teachers but at the same time continue their work in such a way that under the new conditions Grimm and Bopp could not have acted differently. Similarly, for example, in the Russian people we can observe estrangement from their nationality only in individuals trained for this from childhood because of class prejudices. But the educated person who participates in the creation of literature and science in Russian, or who voluntarily and consciously devotes himself to their cause, however he be anathematized by fanatics for the difference between his views and beliefs and those of the common man, not only is not separated from him by an abyss, but, on the contrary, has the right to consider himself more Russian than the common man. They are linked by a unity of elementary modes of thought whose importance is not lessened by the complexity of the tasks for which they are utilized. But a literarily educated man has the advantage over the common man that the latter is influenced merely by an insignificant part of the national tradition, namely, almost exclusively the oral tradition of one area. The educated man, by contrast, comes into contact to various degrees with the centuries-old current of national life; that current is encountered both in its constituent parts and in the final results-the literature of his own time.

In accordance with this, the educated man is incomparably more stable in his nationality than is the common man. In a foreign land, the latter almost completely severs his ties with his native country. Although he learns the alien tongue with difficulty and poorly, he forgets his own with unusual speed, like, for example, the Polish soldiers in the Russian army. The educated man may preserve the better part of the influences of his nationality even in a foreign country. I observe, by the way, that the nonRussian elements in the language of one of the most brilliant Russian writers, who both lived for a long time abroad and died there, stem much less from this circumstance than from upbringing.

Thus we arrive at the conclusion that if civilization lies, among other things, in the creation and development of literatures, and if a literary education-we shall say more, if the portion of literacy that is required to make use of the prayer book, Bible, and calendar in one's native languageis a most powerful means for protecting the individual against denationalization, then civilization not only does not, in and of itself, level nationalities but contributes to their reinforcement. If we suppose that in the future the mixing of tribes on the same territory will increase, then it should be taken into account that by the same time the obstacles to the formation of mixed languages will also have increased. Besides the abovementioned increase in every people of their habituation to their language, these obstacles include the facilitation of the maintenance of communication between remote ends of one and the same nationality. We 
see even now, for example, how the Germans form groups among us and in North America.

But, we are asked, do we really not see that the formation of national literatures presupposes the amalgamation of tribes into a nation united by a literary language? And do not famous philologists tell us that under the influence of the intercourse of thought languages become more and more alike in the most important aspects of their structure? Do we not have the right to continue this tendency until the full merger of at least the IndoEuropean languages? Of course we would have the right to do this if the premises were correct.

Meanwhile, the general outlines of the Aryan languages' history, from which we can judge of the rest, even the most distantly related, appear to us to show their differentiation not only in sounds but also in forms taken into use. Ten, eleven, or twelve Slavic dialects, depending on how they are counted, have come from one common language. Individual peoples have been denationalized, and dialects have died out, but in general this does not constitute a significant factor. It is unlikely that anyone will be able to prove that at some time there were more Slavic dialects than there are now. The evidence for the opposite view is very strong.

Should someone take it into his head to interpret the uniting of tribes into a people, for instance, the Russian people, to mean an actual merging of several dialects and subdialects into one organic whole, as they say, he would be creating a myth. Of course, individual Russian dialects probably arose in consequence of the mixing of tribes and the mutual penetration of elements of two or more neighbouring dialects. But the origin of what we call the Russian language is not such. The Russian language is an aggregate of the Russian dialects.

Nationality from the point of view of language is a concept distinct from the so-called "idea of nationality." Nonetheless these concepts are so interlinked that they need to be carefully differentiated.

It seems obvious that not only the feeling but also the consciousness of national unity, in the sense of intercourse of thought, which is achieved through unity of language, is a very ancient phenomenon; moreover, the time of its origin cannot be determined with accuracy. In contrast, we hear that the idea of nationality was born for the first time at the beginning of our century. Further, it stimulated "the gradual singling out of the personalities of civilized peoples" "from the original indifference of savage peoples." And "the great service of the communication of this stimulus" may be credited to certain individuals - "in Germany, among others, to [Johann Gottlieb] Fichte the elder; among us, to the Slavophiles" (Gradovskii 246). Such opinions are voiced by others as well, but only partially with justification. Of course, unlike Ecclesiastes, we believe that everything under the sun is new and that events do not repeat themselves. 
Our age's idea of nationality bears an imprint of originality, but similar ideas appeared earlier as well. Their generic similarity seems to me to turn on the following. Such an idea is not a necessary feature of a people but a design of individuals and circles that arises from time to time. It is their intention to make certain qualities that are ascribed to the people the guiding principle of the purposeful activity of individuals, societies, and governments of that people-to impart greater energy of activity by exalting its principles. Accordingly, this idea is partly a certain content of thought, partly a general emotional temper of an individual, a circle, a society, and sometimes, in rare critical moments of national life, of a significant portion of the people. In this sense, we see this idea wherever there arises in the people, in response to conflict with other peoples, an apotheosis of certain national features and there is written on a banner something like "God is with us: understand, O nations, and submit," or "civilization is with us," and for this reason, again, "submit."

The idea of nationality is always a kind of messianism. Perceiving the universality of these attributes in the diverse, sometimes opposite views painted over by the "idea of nationality," we arrive at the thought that they are the inevitable consequence of certain conditions of national life, and we lose both the right and the desire to respond with ridicule to phenomena such as our Slavophilism. A well-known poem by Aleksei Khomiakov quite accurately expresses the mood of the Slavophiles and hints at the necessity of the emergence of their teaching as a counter to the similar and just as one-sided teaching of those with a "civilizing mission":

He is not with those who say:

We are the salt of the earth...

He is with those who have not clothed

Arch pride in words of humility...

He is with those who call the nations

Into the spiritual world, into the Lord's temple (Gradovskii 220, 233).

That is, He is with the Slavophiles, even though to an outside observer pride was apparent in their humility. Whether this pride stems from a certain exaggeration of the positive virtues of the people as measured by the "common yardstick" or from a faith in the future, ${ }^{11}$ in the people's high destiny, as yet perceptible only to prophets' eyes, it is impossible to do without this pride as soon as circumstances-whether ours or those in the Germany of the beginning of the present century-require the elimination

11 "Russia cannot be grasped with the mind,

It cannot be measured with the common yardstick;

It has a special stature-

One can only believe in Russia" (Tiutchev, “Umom Rossiiu ne poniat'”). [Trans.] 
of the "spirit of dejection." None are innocent before the court of posterity, but in their own time, and partly in ours, the Slavophiles had the right to say to their opponents, who were seeking truth solely outside themselves:

Civilization for them is a fetish...

However you bow before it, gentlemen,

You will not gain acknowledgment from Europe:

In its eyes you will ever be

Not servants of enlightenment but lackeys (Tiutchev).

These opponents did not see that the German civilizing mission was at least as one-sided. Rebuking the Slavophiles for their constant weakness, although they were a small circle, of speaking in the name of all Russia, the opponents did not see, or acquiesced in the fact, that the bearers of the civilizing mission undertook to make decisions for all mankind. In Rüdiger's article, which attracted their attention and was translated into Russian, we find the following. The idea of nationality, or simply nationality, arose only in our time in defiance of the achievements of civilization solely because that same civilization had done away with certain influences hostile to nationality; it had weakened the asceticism of Christianity, changed its view of dynastic rights, permitted municipal and class insularity, and given the victory to democracy. Thus civilization itself had given rise to a force hostile to the higher interests of mankind, for the national urge to retain differences between peoples in spite of a levelling civilization inevitably turns into an unjust partiality for one's own, into ignorance of the alien, into contempt and enmity to it (Rüdiger 98). Education, inseparable from the aspiration to go beyond the bounds of the merely national, endeavours to disregard inessential differences. The educated mind demands truth from every opinion, beauty from an artistic work, and utility from an institution. But in every people there is much that cannot withstand such examination. A special love of one's own is required in order to regard a tale about past ages of the people's history as truth, a crude daubing of rude ages as a masterful work of art, or an absurd law as a work of the most profound statesmanship. In many nations the crowd believes such things, and knowledgeable men do not dare to contradict it (Rüdiger 119). Nationality can serve both progress and reaction, depending on precisely what it is that has hitherto blocked national development. Thus, for example, in Germany, where freedom and unity are opposed by the sovereigns, national aspirations are liberal, but they are hostile to progress where it is hostile to nationality. "Thus in the Slavic lands German culture, that is, almost all the culture that is there, is hated, and the barbarism of former centuries is manifestly aspired to" (Rüdiger 103). 
Here we must understand by nationality the "idea of nationality," and not nationality in the broad sense; for if by the latter we mean no more than the vessel of civilization, then in that case we shall be unable to understand how the development of the contents might not destroy the vessel (as a bird destroys its shell when it hatches out of its egg) but, on the contrary, strengthen it. Moreover, to all appearances, falsehood is ascribed as a constant feature to the idea of nationality, as a force hostile to civilization. But leaving aside the unconscientious, who exist in every society, educated or not, can it really be said that the uneducated mind takes what it regards in its own terms as false, ugly, or useless as the opposite merely because its compatriots think so? The bearers of the national idea, too, like the admirers of a single universal civilization, consider a thought to be true only until they are persuaded of its falsity. It is extremely unjust to ascribe to them the demand that a personal opinion not in agreement with majority opinion must be suppressed. Even when their ideals are left behind, they are always representatives of the principle of movement, and not of stagnation.

Precisely for this reason, there are much greater grounds to criticize them for a teleological view of history as the fulfillment of a mission, the development of foreordained principles, the incarnation of a preconceived idea. This is noticeable, incidentally, in Aleksandr Gradovskii, despite his efforts to rise above the Slavophiles' point of view. He says, "National creativity is the ultimate goal. It is pointed out by science to every people, and without it the perfection of the human race cannot be achieved" (Gradovskii 146). Gradovskii's peculiarity is that for him the "ultimate goal" is indicated not by Providence but by science, whence the matter loses the greater part of its clarity. What can be meant by the "pointing out of the goal" to the Real by science, that is, ultimately by you personally, for it is common knowledge that science speaks only with the lips of its individual representatives? It cannot be that prior to the work of some professor the Russian people did not have a goal. This should probably be understood as before-the goal was foreordained and merely discovered by science, to put it in an elevated style, or, simply put, by some individual. ${ }^{12}$ But if science cannot at the same time (as in fact is the case) disclose where imitation ends and creativity begins, then the discovery is pointless. Should the perfection of the human race be achieved at some point, so that there is nowhere else to go, science will not be able to detect this. Unlike the national idea, the concept of nationality defined by language seems

\footnotetext{
12 Many scholars besides Gradovskii have the habit of speaking on behalf of science as if they, or some implied person, were in its service with the special mission of standing up for its honour, as if it were an aunt or a sister to them, or some other close person of the weaker sex.
} 
incompatible with the manipulation of such ideas as an ultimate goal and the achievement of perfection. A people, like a language, has countless aims and achieves them precisely by the very fact that it lives. For an earthly observer, however, there is no ultimate goal.

The strangeness of Rüdiger's views is explained by the fact that his "civilization" as a principle common to all mankind is in fact civilization from the viewpoint of the German national idea, which is just as narrow as is the Slavic. He is himself a demonstration of his words that "national views are necessarily one-sided, and national feeling is unthinkable without injustice to foreigners" (Rüdiger 118). In essence, Rüdiger says: Fine if "one's own" is good, as with the Germans; then its preservation and development is legitimate. With the Slavs, however, "one's own" is bad, therefore a love for it and the consequences of such love are crimes against mankind. But who said that "one's own" among the Germans is good and that it should become common to all mankind? Who determined the content of this progressive "one's own" and decided its incompatibility with a foreign form? The bearers of the German national idea themselves, who want to be judges of their own case and pass off their personal standard as absolute. Their ideal ultimately resembles the ideal of the Slavophiles. As the latter dreamed of the denationalization of the Slavic peoples by the Russians, so the former see the universal purpose of the Germans in the denationalization of the neighbouring peoples. Having taken denationalization in its mildest form, we obtain the result that, from the viewpoint of those with a civilizing mission, the development of civilization must be accomplished at others' expense. For teaching the enemies of civilization good, truth, and beauty, the teachers must receive something in the form of material wealth or the less material gratifications associated with power. Thus, here as well we can paraphrase Mephistopheles's words: "Was man den Geist der Zeiten heißt, das ist im Grund der Herren eigner Geist"13_-what you term common to all mankind is merely your own: it is not yet obligatory for all, but you want to make it so, to receive payment for this, and in addition, while so doing, to preserve your conviction that you have laboured gratis for the good of mankind. You say, "God is with us." But you have created this God yourselves, though not without sufficient grounds and need in your personal life. You have not given attention to whether this God is suited for others; whether others desire and are able to believe in him voluntarily, or whether faith in him must be hammered in. If the latter is the case, then even if we assume that world significance lies in store for a certain nationality, we must acknowledge that civilization

13 [This is a quote from Johann Wolfgang von Goethe's Faust. It can be translated as: "Your spirit of the times is, then, / At bottom, your own spirit, gentlemen." Goethe 38-Marko Robert Stech.] 
develops with the advance of all of mankind. And all mankind includes peoples who are being repressed, that is, who are partly being turned into dust and ash, partly being denationalized, and who cannot be themselves under such conditions.

In an attempt to do away with the one-sidedness of the idea of nationality and limit inclinations to Germanization, to Russification, etc., the right of national cultures is advanced, that is, the right of a people to an independent existence and development.

The alteration of views on the relation between the universal and the national, between what is common to an entire people and what is peculiar to part of it, and between this latter and the personal, is explained to a certain degree if it is categorized with the movement of human thought from the acknowledgement of an objective connection between the representation and the represented to the limitation and denial of this connection. A model for this movement can be supplied by any instance in the enormous quantity collected by investigators of the primeval history of thought. In the beginning, for example, man thinks and speaks about a hostile creature such as a wolf and ascribes to his thought not only the portion of being it possesses as a manifestation of his personal thought but a much greater portion, consisting in the direct power to bring nearer, move away, anger, or propitiate this creature. The individual's thought seems here in the beginning a direct lever of external objective being. Subsequently its power is brought by the individual into those bounds that seem natural to us; it is credited with direct influence only on the individual himself. It is evident from this example that by representation there is understood here not only the expression of the thought in a drawing, word, or ritual, but also the thought itself, with respect to its object.

A belief in the identity or objective connection of the representation in this broad sense of the word and the represented is characteristic not only of the childhood of human thought, as many think. This belief merely changes its content with the progress of knowledge. The efforts of thought remove from truth one cover after another, but what in the first moments of discovery seems the naked truth proves subsequently without fail to be only its new shell. The struggle with prejudice is an endless task. We have no yardstick that would give us the right to say that prejudice has decreased in our time. To this day contumely, as humiliating for the person offended, is regarded as an offense by deed and often entails a very real revenge, incomparably greater than what could be expected if attention had been paid here not to a prejudiced identification of word and thing but only to the influence of the word on the opinions of others and on actions resulting therefrom. Vain are efforts of some to fence science off with sharp and immovable boundaries from mythic thought, for the difference here is 
only one of degree. Contrary to those who see the beginning of critical thought in some definite point of history-cannibalism, for instance, not only can be thought to have had rational foundations, but its foundations can be seen to have been laid by critical thought entirely analogous with what is now striving to alter and improve the structure of society.

Even in science the identification of representation and represented in the form of substance of concepts continues to this day. Was it long ago that the soul's faculties were regarded as something real and the soul itself as something real, and not as the mental amalgamation of a number of features? Do not many believe that matter is a thing and all else is rubbish? Was it long ago that it was generally believed that thought common to all mankind was embodied in language in such a way that should we put this thought in front of us and discover some of its properties, we could be sure that our investigation of language would reveal the same properties? This was undoubtedly a scholarly device, but it was analogous with, for example, auguring from a dream or from lines on a ram's shoulder blade events external to those objects and phenomena.

The opposition so customary and necessary for us of thought and object is itself also the substance of thought, for the "absolutely objective," that by which in the end our thought is determined, is completely inaccessible to us. Moreover, what we call the object, when correctly understood, proves also to be thought, but thought not yet separated from perceptions, and still regulated by them. What is called the course of objectification of thought is an imprecise term and consists in equal measure in the acknowledgment of elements of the object as subjective.

Passing on to the common human and the national, let us see how they are treated by Gradovskii, the author of a work that is generally quite good, although in Otechestvennye zapiski (Fatherland Notes) it was portrayed as almost a crime against society.

Up to now the notion that "the idea of mankind is embodied in the history of individual peoples" has been regarded by some as a profound philosophical truth and has been understood as follows: the idea, as embodied in something independent of me who is saying this, is itself independent of me and exists by itself. "But," says Gradovskii, "the relation between what is common to all mankind and what is national is like that between a logical concept and a real phenomenon." "Our conception of that which is common to all mankind is a product . . . of the generalization of individual phenomena." "It does not possess real being" and exists only in a thinking individual and through him (239). This, it seems, is quite clear. Hence the moral that the national, which is living and real, should not and cannot be sacrificed to the common human, which is illusory and abstract.

Meanwhile, the author's resoluteness proves to be shaky. "Is it possible," he [Gradovskii] asks, "that in our opinion the common human is 
only a logical fiction, a fruit of abstraction without significance in the lives of nations? Not at all! That would mean denying the merit of one of the most precious capacities of the human spirit and mind - the ability . . . to form general concepts" (240). So far this is the same thing we saw above. It would even seem to be superfluous to speak of this, since the acknowledgment of the common human as a concept does not imply its denial. But the point is that the author himself, following in the footsteps of his predecessors, verges on mythology when he ascribes to this concept an existence other than that which befits it, as a generalization coming from an individual: "Instead of speaking of a common human civilization, it is more correct to speak about the common human in civilization, that is, about the aggregate of the conditions of culture that must be adopted by a whole group of peoples, however much they differ in everything else" (Gradovskii 237-38). If the common human has compulsory force for all peoples, then it constitutes something more important than other generalizations.

The author goes on to specify these conditions. They are, in the first place, "those conditions without which the normal life of a man and an entire people is unthinkable, whatever the characteristics of its culture ...." For example: personal safety, freedom of conscience, of thought, and of speech, a guarantee of the conditions of public health, of foodstuffs, of education, etc. "The concept of the common human is (here) even the ground for the criticism of national imperfections," for instance, when from this point of view the assertion that "slavery is the natural vocation of the Negro" is negated. In the second place, they are external conditions of the realization of human goals, for example, communications, instruments of exchange, machines, technique in poetry and art, etc. (Gradovskii 240-41).

It is not difficult, however, to object that all this can be treated merely as national. That is to say, for example, on the one hand every people understands personal safety, freedom, etc., differently. On the other hand, a great diversity is to be found even in the utilization and understanding of things that move from one people to another. Thus, for example, a savage may wear a uniform he has been given without a shirt and trousers. Still less noticeable is the common human in methods of production. Does the author, for example, really believe that syllabic versification on Russian soil was equal to that on Polish or French soil? Does he really think that there exist, for instance, in painting and engraving not only two peoples or two schools, but even two artists with identical technique? If the discussion concerned only the possibility of making abstractions out of everything, it would not be worthwhile to adduce individual examples. But the issue is larger, namely, the possibility of criticizing the national from the viewpoint of the common human. Such criticism, however, is just as mythological as was the attempt to deduce the normal conditions of the life of the polar fox, 
or the possibilities of its acclimatization from the characteristics of the genus that embraces the dog, the wolf, the jackal, etc.

But the substantiation of thought is most obvious in the very opposition of the common human as a concept to the national as a real phenomenon. Both of them are real and ideal precisely to the extent that a concept is real and ideal. Thus, a species in zoology and botany has no more right to objective being than does a type of concept. The Russian people, just like the concept of "the common human in civilization," if we look upon it from top to bottom, ${ }^{14}$ that is, in the direction of the elements from which it arose, immediately breaks down into individual parts: tribes, classes, millions of indivisible units in different ages. It would obviously be extremely erroneous to ascribe real existence to the personality in contradistinction to the ideality of the concept of the "people," for the personality, my "I," is also a generalization of content that changes at every moment. The key to unriddling phenomena of personal, family, clan, tribal, and national life is hidden more deeply than in the abstraction called personality. This suggests that opposing the reality of the people to the ideality of mankind is a very poor remedy for the immoderate pretensions of the national idea, which poses as the common human. The sole remedy for such errors of thought consists in keeping the concept open to an influx of new elements. This influx will not be long in destroying the concept and transforming it into a new one. In some cases these speculations seem more dangerous to some than . . . ${ }^{15}$ For example, were someone to say that the concept of a (particular) united people contains incompatible contradictions and therefore collapses, another might think that the pillars of the state and the national edifice would totter because of this. But to calm such apprehensions it can be pointed out that ideas begin to guide life only afterwards, after long periods that are required for their transformation, so to speak, into the black soil of thought, that is, into something that is no longer a subject for discussion.

The advantage of the concept of the national, defined by language, over the common human or the national in the sense of the "idea of nationality," lies in the former's being more objective in the sense that it is less a priori. That is why, for one thing, it more greatly stimulates investigation. Steinthal, after speaking of the appearance of the individual personality as a product of spiritual development from the common ("das Gemeine," the common and, at the same time, the vulgar), provided by nature, continues: "But subsequently the more noble souls ('Geister') overcome the

\footnotetext{
${ }^{14}$ From this point on the manuscript has been lost, and the article is presented as it was printed in Vestnik Evropy [Herald of Europe].

15 A lacuna in the text.
} 
limitedness of individuality to such a degree that they express the general law and ideals ('das allgemeine, das gemeinsame Gesetz und Ideal')" ("Über den Aberglauben" 91). Consequently, in his opinion, the diverging lines of differentiation break in the higher spheres of development and draw together again. A similar thought is voiced by Orest Miller in speaking of the differentiation of an individual and a people. The appearance of independent individual thought and its preservation with the aid of written texts imparts movement to national life:

As it diversifies in the manifestations of its life and moves forward, the people not only does not cease to exist but thereby becomes itself in the full sense. The more individual physiognomies appear in the people, the more all these physiognomies clarify, define, and bring to the surface the general character of the national spirit or the national type. It is precisely in the primitive epoch, that is, in the epoch of almost definite nonexistence of personalities, that peoples differ little among themselves in their mores and spiritual lives. That is why the primitive period of their folklore offers, without any deliberate borrowing from one another, incomparably more similarities than peculiarities. Later on, because of the protracted action of individual thought, which gradually penetrates into folklore, national peculiarities begin to be expressed in it as well. But only in literature - a healthy, independent literature, of course-can the individual physiognomy of a people be expressed definitively and completely.

Meanwhile, in this manifestation of personality the common human elements not only do not disappear but, on the contrary, it is in it that they attain their true final development. Just so, the type of the human face attains its highest and fullest development precisely in those human beings who have a characteristic, formed physiognomy, and not in those in whom nothing is noticeable except the general constituent parts of the human face.

One wants to say of a face in which there are only eyes, a nose, a mouth, etc. ... and in all of which there is nothing special, nothing of the sort that would belong to that face alone: "What a vulgar and inhuman face that is!" The main thing in a human type is precisely the capacity, in all human faces, of becoming something unique in each type while preserving its common elements. For this reason, that which expresses most fully not the physical but the spiritual type of the human race-literature-attains its full development and brings to light the entire depth of the human spirit with full clarity precisely when there appear in literature the works of individuals, that is, individual creativity, each of these individuals being unique in its type (Miller 18-19).

Here it is necessary first of all to do away with the erroneous thought (or, perhaps, merely the erroneous, needlessly mythological expression) that "individual creativity brings to light the entire depth of the human 
spirit" (Miller). As if this depth did not come into existence only when it is revealed! As if the completeness of its development were something given in advance and merely hidden and asleep for the time being, like a spark in a flint according to the mythological view. Further, it is true that the differentiation of peoples is connected with the individualization of personalities in them. To believe, however, that the differentiation of peoples is also an aspiration to the common human is the same as believing that when man rises above his animal ancestors, he is moving toward common animality. We can conceive of an approximation of the common human only behind the present level of development of mankind, where Miller, too, sees a similarity between peoples that is independent of borrowing. But in the direction of the future, the common human, in the sense of similarity, can only decrease. It increases only in the sense of strength of mutual influence, just as with the emergence of man his influence on animals and plants is strengthened, and vice versa.

\section{Works Cited}

Aksakov, Ivan. Biografiia Fedora Ivanovicha Tiutcheva. Typ. M. G. Volchaninova, 1886.

Bedzhgot, Uolter. Estestvoznanie i politika. St. Petersburg, 1874.

Goethe, Johann Wolfgang von. Faust: A Tragedy. Translated by Charles. T. Brooks, Thicknor and Fields, 1857.

Gradovskii, Aleksandr. Natsional'nyi vopros $v$ istorii $i$ literature. Izd. D. E. Kozhanchikova, 1873.

Grimm, Jacob. Kleine Schriften. Vol. 4, F. Dümmler, 1869.

Humboldt, Wilhelm von. Über die Verschiedenheit des menschlichen Sprachbaues. Druckerei der Königlichen Akademie der Wissenschaften, 1836.

Mommsen, Tycho. Die Kunst des deutschen Übersetzens aus neueren Sprachen. Leipzig, 1858.

Miller, Orest. Opyt istoricheskogo obozreniia russkoi slovesnosti. Typ. I. A. Gorchakova, 1863.

Rüdiger, Ludwig. "Über die Nationalität.” Zeitschrift für Völkerpsychologie und Sprachwissenschaft, vol. 3, 1865, pp. 95-130.

Steinthal, Heymann. "Über den Aberglauben.” Zeitschrift für Völkerpsychologie und Sprachwissenschaft. Vol. 2, 1862, pp. 83-101.

---. "Zur Religionsphilosophie." Zeitschrift für Völkerpsychologie und Sprachwissenschaft, vol. 8, 1875, pp. 257-99.

Turgenev, Ivan. Rudin. Polnoe sobranie sochynenii v" 12 tomakh. Vol. 4, Izdanie A. F. Maiksa, 1898, pp. 299-437.

---. Polnoe sobranie pisem I. S. Turgeneva. 1840-1883 gg. 0-vo dlia posobiia nuzhdaiushchimsia literatoram i uchenym, 1884. 